\title{
Cardiovascular and all-cause mortality attributable to loneliness in older Swedish men and women
}

\author{
Masuma Novak ${ }^{*}$ D, Margda Waern, Lena Johansson, Anna Zettergren, Lina Ryden, Hanna Wetterberg, \\ Pia Gudmundsson and Ingmar Skoog
}

\begin{abstract}
Background: This study examined whether loneliness predicts cardiovascular- and all-cause mortality in older men and women.

Methods: Baseline data from the Gothenburg H70 Birth Cohort Studies, collected during 2000 on 70-year-olds born 1930 and living in Gothenburg were used for analysis $(n=524)$. Mortality data were analyzed until 2012 through Swedish national registers.

Results: Perceived loneliness was reported by $17.1 \%$ of the men and $30.9 \%$ of the women in a face-to-face interview with mental health professional. A total of 142 participants died during the 12-year follow-up period, with 5334 person-years at risk, corresponding to 26.6 deaths/1000 person-years. Cardiovascular disease accounted for $59.2 \%$ of all deaths. The cumulative rates/1000 person-years for cardiovascular mortality were 20.8 (men) and 11.5 (women), and for all-cause mortality 33.8 (men) and 20.5 (women), respectively. In Cox regression models, no significant increased risk of mortality was seen for men with loneliness compared to men without loneliness (cardiovascular mortality HR 1.52, 95\% Cl 0.78-2.96; all-cause HR 1.32, 95\% Cl 0.77-2.28). Increased risk of cardiovascular mortality was observed in women with loneliness compared to those without (HR 2.25 95\% Cl 1.144.45), and the risk remained significant in a multivariable-adjusted model (HR 2.42 95\% Cl 1.04-5.65).

Conclusions: Loneliness was shown to be an independent predictor of cardiovascular mortality in women. We found no evidence to indicate that loneliness was associated with an increased risk of either cardiovascular- or allcause mortality in men.
\end{abstract}

Keywords: Loneliness, CVD, Mortality, Sweden, Epidemiology

\section{Background}

Loneliness is a subjective, negative emotional state, generally defined as perceiving less social contacts than desired [1]. Loneliness may be experienced by people of all ages, however, with advancing age, social contacts are reduced due to factors, such as losses of spouse or

\footnotetext{
* Correspondence: masuma.novak@gu.se

Institute of Neuroscience and Physiology, Department of Psychiatry and Neurochemistry, Unit of Psychiatric Epidemiology, Sahlgrenska Academy, University of Gothenburg, Wallinsgatan 6, 43141 Mölndal, Sweden
}

friends or mobility impairments, resulting in a higher prevalence of loneliness in elderly populations [2]. A large body of evidence suggests that loneliness is a major risk factor for poor mental and physical health in later life [3]. For instance, feeling of loneliness is reported to be associated with increased risks of cardiovascular diseases (CVD), depressive symptoms, impaired cognitive performance, and dementia [3]. Although there is considerable literature on the impact of loneliness on morbidity, there is modest data on its effect on mortality [3].

(C) The Author(s). 2020, corrected publication 2020. Open Access This article is licensed under a Creative Commons Attribution 4.0 International License, which permits use, sharing, adaptation, distribution and reproduction in any medium or format, as long as you give appropriate credit to the original author(s) and the source, provide a link to the Creative Commons licence, and indicate if changes were made. The images or other third party material in this article are included in the article's Creative Commons licence, unless indicated otherwise in a credit line to the material. If material is not included in the article's Creative Commons licence and your intended use is not permitted by statutory regulation or exceeds the permitted use, you will need to obtain permission directly from the copyright holder. To view a copy of this licence, visit http://creativecommons.org/ licenses/by/4.0/. The Creative Commons Public Domain Dedication waiver (http://creativecommons.org/publicdomain/zero/1. 0/) applies to the data made available in this article, unless otherwise stated in a credit line to the data. 
These studies have reported higher rates of mortality among individuals with loneliness [4-11]. However, findings across these studies are inconsistent on whether loneliness independently predicts mortality risk after adjusting for initial health and social factors. The aim of the present study was to examine whether loneliness independently predicts cardiovascular- and all-cause mortality in older people after adjusting for initial health status, health behaviors, depression, living alone and economic situation.

\section{Methods}

\section{Study population}

The Gothenburg H70 Birth Cohort Studies (the H70 studies) are ongoing population-based longitudinal studies of health and ageing. Full details of these studies have been reported elsewhere [12-16]. In brief, initiated in 1971 , the H70 studies are a series of cohort studies of older men and women living in Gothenburg, Sweden. Seventy-year-old men and women listed in national population registers in Gothenburg were systematically selected based on their birth dates and they underwent extensive medical, social, psychiatric, and physical examinations.

For the purpose of the present study, baseline data on the 1930 birth cohort collected during 2000 was used $(n=$ 524, response rate 70\%). Forty-seven percent of nonparticipants was surveyed for a shorter health interview. Participants and non-participants were similar regarding self-rated health, history of myocardial infarction, diabetes or smoking status, but married men were significantly overrepresented among participating men [17].

\section{Assessment of loneliness}

Self-perceived feeling of loneliness was assessed by a single question as 'do you feel lonely?' There were four alternative responses where 1 indicated never feeling lonely, 2 seldom, 3 sometimes, and 4 very often (see Table 1 for sample distribution). The four categories were then merged into a dichotomous variable as $0=$ not lonely (responses $1-2$ ), and $1=$ lonely (responses $3-4$ ).

\section{Mortality}

Based on unique personal identification numbers and using the Swedish national registers (the national population register and the national cause of death register), cohorts were followed for 12 years from the date of their baseline examination or until death. Cardiovascular deaths were those with International Classification of Diseases, 10th Revision (ICD-10) codes I.00-I.99.

\section{Other covariates}

Adverse socioeconomic status, health and health related behavioral factors that have previously been shown to be associated with loneliness [18-20] were included as possible confounding factors. Current perceived economic situation was assessed using a seven-point scale ranging from excellent to very bad (coded from 1 to 7 ). The seven-point scale was then merged into three categories: good (scale points 1-3, excellent, very good, good), Average (scale point 4), and poor (scale points 5-7, not very good, bad, very bad). Living alone was categorized as individuals who are single, or divorced, or widowed and live alone versus individuals who live with a partner (married/cohabiting/having partner but lives separate or live-apart-together or occasionally live together, Swedish term is 'särbo') or with someone else. Smoking status was categorized as current smoker (regular or occasional), previous smoker, and never smoker. Leisure time physical activity was defined as moderate/regular versus inactive. Alcohol consumption was measured with questions regarding weekly consumption of beer, wine, and spirits in centiliters [21] during the past month. Based on these volumes, average weekly grams of alcohol consumption were calculated using conversion factors based on average alcohol concentration by volume (spirits 1 $\mathrm{cl}=3 \mathrm{~g}$, wine $1 \mathrm{cl}=1 \mathrm{~g}$, beer $>3.5 \% 1 \mathrm{cl}=1 / 3 \mathrm{~g})$. Body mass index (BMI) was calculated from measured weight and height (weight in $\mathrm{kg} /$ height in $\mathrm{m}^{2}$ ). Previous history of having (yes/no) cancer, diabetes, coronary heart disease and stroke was based on self-report as well as from medical examinations conducted by a study physician. Systolic and diastolic blood pressure (SBP, DBP) were measured in the sitting position after a minimum of 5 min of rest. Blood samples were drawn from an antecubital vein and serum triglyceride measurement was determined according to standard laboratory procedures. ADL disability was defined based on a six-item scale of activities of daily living (ADL). The ADL scale measured self-reported difficulties in performing daily life activities

Table 1 Number and percentages of men and women in each of the four response categories of self-perceived feelings of loneliness

\begin{tabular}{|c|c|c|c|c|c|}
\hline & $\begin{array}{l}\text { All } \\
N\end{array}$ & $\begin{array}{l}\text { Never (response 1) } \\
\mathrm{n}(\%)\end{array}$ & $\begin{array}{l}\text { Seldom (response 2) } \\
\text { n (\%) }\end{array}$ & $\begin{array}{l}\text { Sometimes (response 3) } \\
\mathrm{n}(\%)\end{array}$ & $\begin{array}{l}\text { Often (response 4) } \\
\text { n (\%) }\end{array}$ \\
\hline Men & 240 & $147(61.3)$ & $52(21.7)$ & 39 (16.3) & $2(0.8)$ \\
\hline Women & 272 & $104(38.2)$ & 84 (30.9) & $70(25.7)$ & $14(5.1)$ \\
\hline All & 512 & $251(49.0)$ & $136(26.6)$ & $109(21.3)$ & $16(3.1)$ \\
\hline
\end{tabular}


including transferring, dressing, bathing, using toilet, eating, and continence. Each item was coded as $0=$ no need of help from another person, and $1=$ need help. A composite index was created by summing up all the six items ranging from 0 to 6 (need no help to need help in all six activities). The index was then dichotomized as 0 (no ADL disability) and 1 (ADL disability, scale 1-6). Based on symptoms elucidated during a psychiatric examination, major depression was diagnosed according to the DSM-5 criteria (American Psychiatric Association) [22], and minor depression according to the DSM-IV research criteria [23]. Definition of these variables has been described previously [24].

\section{Statistical analysis}

Using descriptive statistics, differences in the distribution of baseline characteristics in men and women according to their loneliness status were examined using the Pearson $\mathrm{x}^{2}$-test for categorical variables and Student's t-test for continuous variables. Descriptive statistics are presented as percentages or mean values with standard deviations (SD). All P-values are two-sided and values of $<0.05$ were considered statistically significant. The survival function for the 12-year period according to loneliness status was assessed using the Kaplan Meier method, and the log-rank test was used to evaluate group differences. Cox proportional hazard regression models were used to study the association between loneliness status at baseline and cardiovascular and allcause- mortality during 12-year follow-up. Both unadjusted and multivariable adjusted regressions were carried out separately for cardiovascular- and all-cause mortality. Factors that were shown to be associated with loneliness were included in multivariable models, where all the selected variables were entered simultaneously. Estimates derived from Cox regressions are presented in graphical format showing hazard ratios [21] and 95\% CI. Statistical analyses were performed using SPSS, Windows version 25.0 (SPSS Inc., Chicago, IL, USA) and graphics were produced using $\mathrm{R}$ version 3.4.3 (The $\mathrm{R}$ Foundation for Statistical Computing).

\section{Results}

The current analyses were conducted on 512 participants (240 men, 272 women) after exclusion of 12 individuals with missing data on loneliness. A total of 125 (24.4\%) participants reported being lonely at baseline. The prevalence of loneliness was $17.1 \%(n=41)$ in men and $30.9 \%(n=84)$ in women $(p=0.001)$.

\section{Loneliness and background characteristics}

Table 2 presents background characteristics of men and women according to their loneliness status. Men with loneliness reported more often poor economic status, living alone, and physical inactivity and were more often diagnosed with depression than men with no loneliness. No significant differences were observed regarding smoking, alcohol consumption, BMI, and history of any health related variables. Women with loneliness more often reported poor economic status, chronic bronchitis, and living alone, and were more often diagnosed with depression than women without loneliness. No significant differences were observed regarding smoking, physical activity, alcohol consumption, BMI, or history of other health related variables.

\section{Gender, loneliness and mortality}

A total of $142(27.7 \%)$ participants died during the 12year follow-up period, with a median follow-up of 11 years and 5334 person-years at risk, corresponding to 26.6 deaths per 1000 person-years. Cardiovascular disease accounted for $59.2 \%(n=84)$ of all deaths, which corresponds to 15.8 deaths per 1000 person-years. The cumulative rates per 1000 person-years for cardiovascular mortality were 20.8 (men) and 11.5 (women), and for all-cause mortality were 33.8 (men) and 20.5 (women), respectively.

Kaplan Meier analysis showed no significant difference in survival between men with and without loneliness for either cardiovascular- or all-cause mortality (log rank, $p>0.05$ ) (Fig. 1a and b). For women, Kaplan Meier curves showed no significant difference in all-cause mortality by loneliness status (Fig. 1c), but a lower survival rate was observed among women with loneliness compared to women with no loneliness regarding cardiovascular mortality ( $\log$ rank, $p=0.017$ ) (Fig. 1d).

Figure 2 presents HRs and 95\% CI of (a) cardiovascular and (b) all-cause mortality according to gender and loneliness status. Similar to Kaplan Meier results, no significant increased risk of mortality was observed for men with loneliness compared to men with no loneliness for both cardiovascular (HR 1.52 95\% CI 0.78-2.96) and allcause mortality (HR 1.32 95\% CI 0.77-2.28). In all-cause mortality, no significant increased risk of mortality was seen for women with loneliness compared to women with no loneliness (HR 1.64 95\% CI 0.98-2.76). However, women with loneliness had significantly higher risks of cardiovascular mortality compared to women with no loneliness (HR 2.25 95\% CI 1.14-4.45). The high risks of cardiovascular mortality in women remained significant in the multivariable-adjusted model (2.42 95\% CI 1.04-5.65).

\section{Discussion}

This study examined if loneliness at age 70 was prospectively associated with cardiovascular- and all-cause mortality over a 12-year follow-up period, after controlling for initial health status, health behaviors, depression, 
Table 2 Distribution of baseline characteristics among men and women according to their perceived loneliness status $(N=512)$

\begin{tabular}{|c|c|c|c|c|c|c|}
\hline & \multicolumn{3}{|l|}{$\begin{array}{l}\text { Men } \\
\boldsymbol{N}=240\end{array}$} & \multicolumn{3}{|l|}{$\begin{array}{l}\text { Women } \\
\boldsymbol{N}=272\end{array}$} \\
\hline & $\begin{array}{l}\text { Lonely } \\
\boldsymbol{N}=41\end{array}$ & $\begin{array}{l}\text { Not lonely } \\
\mathbf{N}=199\end{array}$ & $\boldsymbol{p}$-value & $\begin{array}{l}\text { Lonely } \\
\boldsymbol{N}=84\end{array}$ & $\begin{array}{l}\text { Not lonely } \\
\mathbf{N}=188\end{array}$ & $\boldsymbol{p}$-value \\
\hline \multicolumn{7}{|c|}{ Current perceived economic situation } \\
\hline Good & $47.5(19)$ & $77.7(150)$ & & $48.8(39)$ & $72.2(132)$ & \\
\hline Average & $27.5(11)$ & $15.6(30)$ & & $38.8(31)$ & $17.8(32)$ & \\
\hline Poor & $25.0(10)$ & $6.7(13)$ & 0.000 & $12.5(10)$ & $10.0(18)$ & 0.001 \\
\hline Living alone & $52.5(21)$ & $9.1(18)$ & 0.000 & $60.8(48)$ & $39.2(71)$ & 0.001 \\
\hline \multicolumn{7}{|l|}{ Smoking status: } \\
\hline Never smoker & $22.0(9)$ & $33.3(66)$ & & $51.2(42)$ & $62.5(115)$ & \\
\hline Previous smoker & $53.6(22)$ & $53.5(106)$ & & $25.6(21)$ & $23.9(44)$ & \\
\hline Current smoker & $24.4(10)$ & $13.2(26)$ & 0.119 & $23.2(19)$ & $13.6(25)$ & 0.109 \\
\hline \multicolumn{7}{|l|}{ Physical activity: } \\
\hline Regular & $38.5(15)$ & $64.4(125)$ & & $32.5(25)$ & $35.8(63)$ & \\
\hline Inactive & $61.5(24)$ & $35.6(69)$ & 0.003 & $67.5(52)$ & $64.2(113)$ & 0.609 \\
\hline BMI & $27.13 \pm 3.49$ & $26.88 \pm 3.95$ & 0.704 & $26.63 \pm 4.04$ & $27.22 \pm 4.69$ & 0.330 \\
\hline Alcohol (gm/per week) & $51.18 \pm 64.61$ & $76.29 \pm 108.27$ & 0.071 & $25.69 \pm 31.14$ & $34.03 \pm 52.14$ & 0.228 \\
\hline \multicolumn{7}{|l|}{ Health related variables: } \\
\hline SBP (mm Hg) & $151.97 \pm 22.46$ & $157.71 \pm 20.40$ & 0.146 & $151.43 \pm 23.85$ & $153.70 \pm 22.07$ & 0.504 \\
\hline $\mathrm{DBP}(\mathrm{mm} \mathrm{Hg})$ & $84.76 \pm 8.94$ & $87.81 \pm 9.95$ & 0.103 & $85.40 \pm 11.85$ & $84.36 \pm 10.47$ & 0.517 \\
\hline Triglyceride (mmol/l) & $1.30+0.54$ & $1.39 \pm 0.57$ & 0.386 & $1.40 \pm 0.56$ & $1.41 \pm 0.85$ & 0.995 \\
\hline Diabetes & $12.2(5)$ & $11.2(22)$ & 0.850 & $11.5(9)$ & $9.0(16)$ & 0.536 \\
\hline $\mathrm{CHD}$ & $17.1(7)$ & $10.7(21)$ & 0.246 & $5.0(4)$ & $5.5(10)$ & 0.877 \\
\hline Stroke & $2.4(1)$ & $5.1(10)$ & - & $9.8(8)$ & $7.0(13)$ & 0.445 \\
\hline Cancer & $12.2(5)$ & $15.3(30)$ & 0.610 & $18.2(14)$ & $12.6(22)$ & 0.248 \\
\hline Chronic bronchitis & $19.5(8)$ & $13.2(26)$ & 0.293 & $25.6(20)$ & $15.2(27)$ & 0.046 \\
\hline Arthritis & $17.1(7)$ & $17.3(34)$ & 0.966 & $34.6(27)$ & $31.8(56)$ & 0.661 \\
\hline ADL disability & $17.9(7)$ & $9.2(17)$ & 0.108 & $14.9(11)$ & $10.6(18)$ & 0.343 \\
\hline \multicolumn{7}{|l|}{ Depression: } \\
\hline No & $68.4(26)$ & $95.7(180)$ & & $61.3(49)$ & $92.8(168)$ & \\
\hline Minor & $21.1(8)$ & $4.3(8)$ & & $25.0(20)$ & $5.5(10)$ & \\
\hline Major & 10.5 (4) & 0 & 0.000 & $13.8(11)$ & 1.7 (3) & 0.000 \\
\hline
\end{tabular}

Values presented in this table are mean \pm SD or percentage with number of subjects in parenthesis

$B M I$ Body mass index (wt in $\mathrm{kg} / \mathrm{ht}$. in $\mathrm{m}^{2}$ ), SBP Systolic blood pressure, DBP Diastolic blood pressure, CHD Coronary heart disease

and other social factors. We found that loneliness was an independent predictor of cardiovascular mortality in women, while there was no significant association with all-cause mortality. Among men, we found no evidence of an association between loneliness and subsequent death whether cardiovascular- or all-cause both in unadjusted or multivariable-adjusted models.

The strengths of the study included the populationbased samples of both men and women and the comprehensive examinations data on socio-demographic factors, medical history, and clinical- and physical measurements, including loneliness status. However, this study also had a number of limitations. First, although the response rate at baseline was $70 \%$, which is higher than in many other studies [25], we cannot exclude the possibility that participants were healthier than non-participants. Although a short health survey in non-participants revealed that participants and non-participants were similar in terms of health history and health related behaviors, married men were overrepresented among participating men [17]. This may imply that lonely men are underrepresented in the sample, as unmarried status is strongly associated with loneliness [19], which may have caused selection bias in our study. Another limitation was the definition of loneliness, which was assessed with a single- 

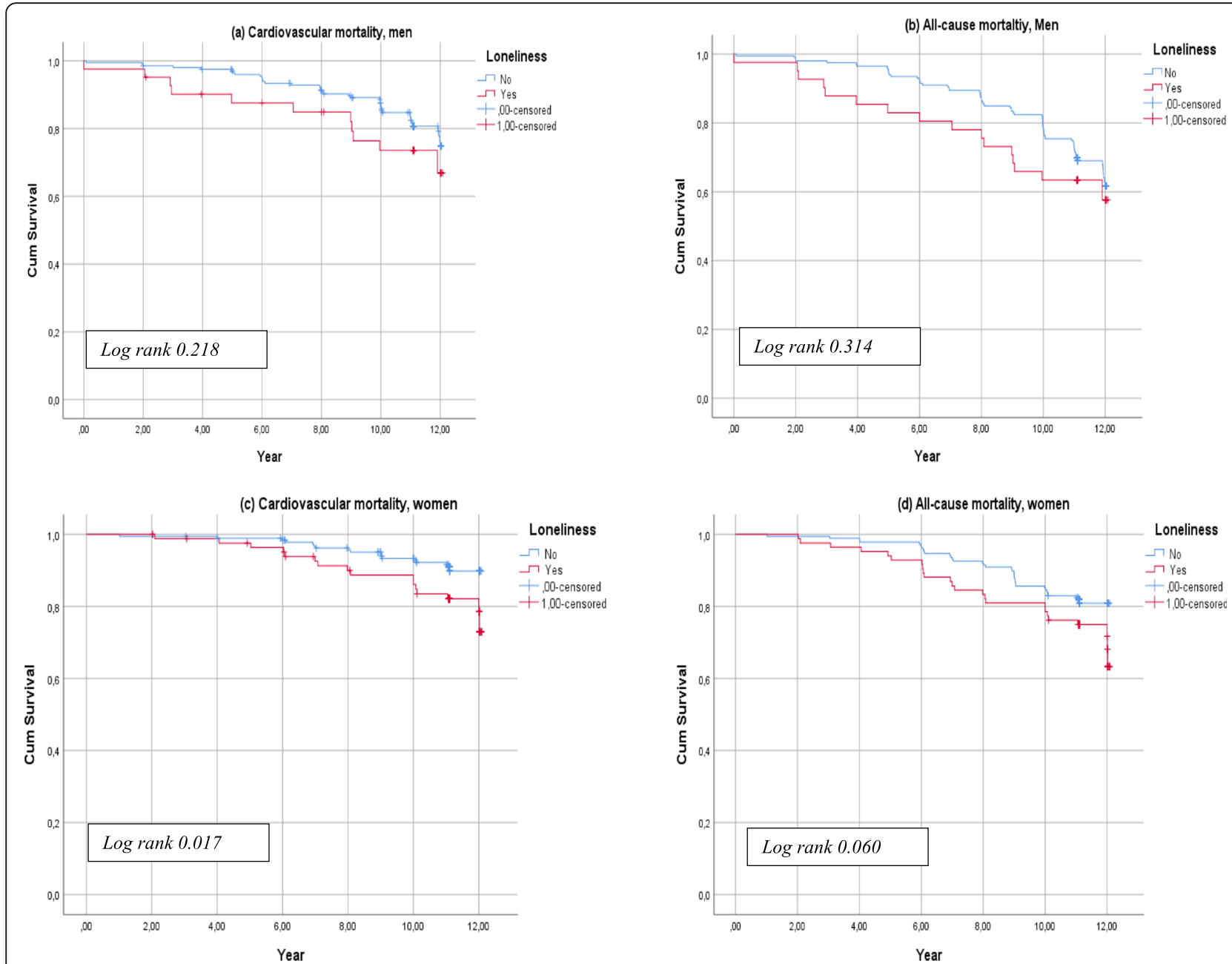

Fig. 1 Kaplan-Meier survival estimates for 12-years follow-up according to perceived loneliness status for (a) cardiovascular mortality, men; (b) allcause mortality, men; (c) cardiovascular mortality, women; and (d) all-cause mortality, women

(a) Cardiovascular Mortality

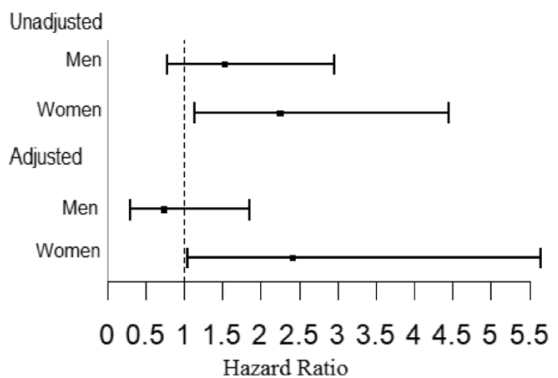

(b) All-cause Mortality

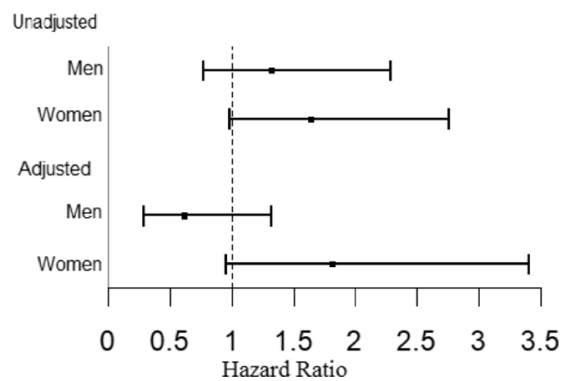

Note: Adjusted variables for men are poor economy, living alone, physical inactivity, and depression. Adjusted variables for women are poor economy, living alone, chronic bronchitis, and depression.

Fig. 2 Cox proportional hazard ratios (HR) and 95\% confidence intervals (Cl) of (a) cardiovascular mortality and (b) all-cause mortality in men and women with loneliness. Note: Adjusted variables for men are poor economy, living alone, physical inactivity, and depression. Adjusted variables for women are poor economy, living alone, chronic bronchitis, and depression 
item question. This may result in underreporting due to the stigma associated with being identified as lonely $[2,26]$. Therefore, this single measurement may not capture the overall influence of loneliness on mortality. This single item question of loneliness, however, is most common and a widely used measure [3], which previously has been shown to predict mortality $[5,7,9]$.

As expected, feeling lonely was more common in women than in men. A recent review concluded that women are more likely to report loneliness than their male counterparts regardless of country studied and the classification of loneliness used [19]. One possible explanation for the greater loneliness experienced by older women may be that they are more willing to admit socially unacceptable feelings than men [1], and that disclosing loneliness may be more socially accepted in women than in men [27].

Findings across previous studies on loneliness and allcause mortality are inconsistent as to whether loneliness independently predicts mortality risk after adjusting for initial health status, health behaviors, depression, and other social factors. The lack of association between loneliness and all-cause mortality found in our present study is similar to several previous studies conducted in Amsterdam [11], France [7], England [10], and China [5]. Two studies conducted in the USA, however, reported that loneliness was an independent predictor of all-cause mortality after adjusting for prior health and health behavior and depression $[4,8]$. Similarly, a recent meta-analysis reported that loneliness is associated with all-cause mortality in both gender but this effect is slightly stronger in men than in women [28]. On the other hand, the Amsterdam study of the elderly (AMSTEL) on 4004 older men and women aged 65-84 years have shown that loneliness is an independent risk factor for all-cause mortality in men but not in women [29]. These inconsistent findings across studies may be related to varying study designs, sample size, methods and follow-up periods, but also differences in cultural settings.

Studies concerning long-term longitudinal associations between loneliness and cardiovascular death are scarce. To our knowledge, our study is the 2nd to examine loneliness in relationship to cardiovascular death in a populationbased sample of men and women. The first study was conducted using UK biobank data on 466,901 men and women by Elovainio M, et. al. and reported that loneliness was not independently associated with cardiovascular mortality for both genders in multivariable adjusted models [6]. Our study result partly contradicts the study by Elovainio $\mathrm{M}$, et. al., as we observed an independent association between loneliness and cardiovascular mortality in women but not in men. Possible mechanisms by which loneliness contribute to cardiovascular mortality, which is observed in our study, may be that loneliness affects cardiovascular health by altering biomarkers and shaping health behavior that are associated with increased CVD risks. For example, loneliness has been associated with elevated blood pressure [18], elevated triglycerides level [20], CHD [30], smoking, and physical inactivity [19]. In our study, no associations were found in women between loneliness and baseline SBP, DBP, CHD, triglyceride level or most of the prior health variables including smoking and physical activity. However, women with loneliness more often reported poor economic status, chronic bronchitis, and living alone, and were more often diagnosed with depression, compared to those without loneliness. Loneliness predicted cardiovascular mortality in women after adjusting for the associated factors suggesting that loneliness alters physiology at a more fundamental level. Future research should include efforts to examine how physiological processes contribute to the effect of loneliness on mortality.

\section{Conclusions}

Loneliness was an independent predictor of cardiovascular mortality in women, while there was no evidence to indicate that loneliness was associated with an increased risk of either cardiovascular- or all-cause mortality in men. Our results emphasizes the importance of considering women with loneliness as a high-risk group to target for public health and medical care efforts in reducing cardiovascular mortality.

\section{Abbreviations}

CVD: Cardiovascular disease; CHD: Coronary heart disease; ICD: International Classification of Diseases; BMI: Body mass index; SBP: Systolic blood pressure; DBP: Diastolic blood pressure; ADL: Activities of daily living; SD: Standard deviations; $\mathrm{Cl}$ : Confidence interval

\section{Acknowledgements}

The authors thank participants and interviewers of the study.

\section{Authors' contributions}

$\mathrm{MN}$ and IS designed the study. MN ran all the analyses, interpreted the results, and wrote the first draft of the manuscript. MN, MW, LJ, AZ, LR, HW $P G$ and IS revised the draft critically and have approved the final text.

\section{Funding}

The study was financed by grants from the Swedish state under the agreement between the Swedish government and the county councils, the ALFagreement (ALF 716681), Stena Foundation, Swedish Research Council (11267, 2005-8460, 2007-7462, 2012-5041, 2015-02830, 2019-01096, 2013-8717, NEAR 2017-00639), Swedish Research Council for Health, Working Life and Wellfare (2004-0145, 2006-0596, 2008-1111, 2010-0870, 2013-1202, 2018-00471, 2001-2646, 2003-0234, 2004-0150, 2006-0020, 2008-1229, 2012-1138, AGECAP 2013-2300, 2013-2496), Konung Gustaf V:s och Drottning Victorias Frimurarestiftelse, Hjärnfonden (FO2014-0207, FO2016-0214, FO2018-0214, FO2019-0163), Alzheimerfonden, Eivind och Elsa K:son Sylvans stiftelse, The Alzheimer's Association Zenith Award (ZEN-01-3151), The Alzheimer's Association Stephanie B. Overstreet Scholars (IIRG-00-2159), The Bank of Sweden Tercentenary Foundation, Stiftelsen Söderström-Königska Sjukhemmet, Stiftelsen för Gamla Tjänarinnor, Handlanden Hjalmar Svenssons Forskningsfond. The funding bodies had no role in the design of the study and collection, analysis, and interpretation of data and in writing the manuscript. Open access funding provided by University of Gothenburg. 


\section{Availability of data and materials}

The data supporting this article can be made available from the corresponding author on reasonable request.

\section{Ethics approval and consent to participate}

All participants gave written informed consent to participate in the study. The study complied with the Declaration of Helsinki principles, and was approved by the Regional Ethics Committee for Medical Research at the University of Gothenburg.

\section{Consent for publication}

Consent for publication does not apply for this manuscript.

\section{Competing interests}

The authors declare that they have no competing interests.

Received: 23 January 2020 Accepted: 4 June 2020

Published online: 09 June 2020

\section{References}

1. Peplau LA, Perman D. Loneliness: a sourcebook of current theory, research and therapy. In: Peplau LA, Perman D, editors. Perspective on loneliness. New York: Wiley; 1982. p. 1-8.

2. Pinquart M, Sörensen S. Influences on loneliness in older adults: a metaanalysis. Basic Appl Soc Psychol. 2001;23:245-66.

3. Ong AD, Uchino BN, Wethington E. Loneliness and health in older adults: a mini-review and synthesis. Gerontology. 2016;62(4):443-9. https://doi.org/10. 1159/000441651 PubMed PMID: 26539997; PubMed Central PMCID: PMCPMC6162046.

4. Luo Y, Hawkley LC, Waite LJ, Cacioppo JT. Loneliness, health, and mortality in old age: a national longitudinal study. Soc Sci Med. 2012;74:907-14.

5. Luo Y, Waite LJ. Loneliness and mortality among older adults in China. J Gerontol B Psychol Sci Soc Sci. 2014;69:633-45.

6. Elovainio M, Hakulinen C, Pulkki-Råback L, Virtanen M, Josefsson K, Jokele M, et al. Contribution of risk factors to excess mortality in isolated and lonely individuals: an analysis of data from the UK Biobank cohort study. Lancet Public Health. 2017:2:e260-6.

7. Maturin $T$, Nadine $S T$, Ralitsa $S$, Céline $M$, Mélanie $C$, Hélène $A$, et al. Feelings of loneliness and living alone as predictors of mortality in the elderly: the PAQUID study. Psychosom Med. 2016;78:904-9.

8. Perissinotto CM, Stojacic Cl, Covinsky KE. Loneliness in older persons: a predictor of functional decline and death. Arch Intern Med. 2012;172: 1078-84.

9. Shiovitz-Ezra S, Ayalon L. Situational versus chronic loneliness as risk factors for all-cause mortality. Int Psychogeriatr. 2010;22(3):455-62.

10. Steptoe A, Shankar A, Demakakos P, Wardle J. Social isolation, loneliness, and all-cause mortality in older men and women. PNAS. 2013;110(15):5797-801.

11. Tjalling JH, Theo GT, Dorly JHD, Natasja S, Rien V, Jack D, et al. Impact of Ioneliness and depression on mortality: results from the longitudinal ageing study Amsterdam. Br J Psychiatry. 2016;209:127-34. https://doi.org/10.1192/ bjp.bp. 115.168005 .

12. Berg S. Psychological functioning in 70- and 75-year-old people. A study in an industrialized city. Acta Psychiatr Scand Suppl. 1980;288:1-47.

13. Eriksson BG, Mellstrom D, Svanborg A. Medical-social intervention in a 70year-old Swedish population. A general presentation of methodological experience. Compr Gerontol C. 1987;1:49-56.

14. Rinder L, Roupe S, Steen B, Svanborg A. Seventy-year-old people in Gothenburg. A population study in an industrialized Swedish city. Acta Med Scand. 1975;198:397-407.

15. Rydberg ST, AhIner F, Blennow K, Dahlin-Ivanoff S, Falk H, Havstam JL, et al. The Gothenburg H70 Birth cohort study 2014-16: design, methods and study population. Eur J Epidemiol. 2019;34(2):191-209. https://doi.org/10 1007/s10654-018-0459-8 PubMed PMID: 30421322; PubMed Central PMCID: PMCPMC6373310

16. Steen B, Djurfeldt $H$. The gerontological and geriatric population studies in Gothenburg, Sweden. Z Gerontol. 1993;26:163-9.

17. Bergh I, Steen G, Waern M, Johansson B, Oden A, Sjostrom B, et al. Pain and its relation to cognitive function and depressive symptoms: a Swedish population study of 70-year-old men and women. J Pain Symptom Manag. 2003;26:903-12.
18. Hawkley LC, Masi CM, Berry JD, Cacioppo JT. Loneliness is a unique predictor of age-related differences in systolic blood pressure. Psychol Aging. 2006;21(1):152-64.

19. Jiska CM, Haim H, Yaffa L, Vera S. Correlates and predictors of loneliness in older-adults: a review of quantitative results informed by qualitative insights. Int Psychogeriatr. 2016;4(28):557-76. https://doi.org/10.1017/ S1041610215001532

20. Sorkin D, Rook KS, Lu JL. Loneliness, lack of emotional support, lack of companionship, and the likelihood of having a heart condition in an elderly population. Ann Behav Med. 2002;24:290-8.

21. Wethington E, Eccleston C, Gay G, Gooberman-Hill R, Schofield P, Bacon E, et al. Establishing a research agenda on mobile health technologies and laterlife pain using an evidence-based consensus workshop approach. 2018.

22. American Psychiatric Association. Diagnostic and statistical manual of mental disorders. Arlington: American Psychiatric Association; 2013.

23. American Psychiatric Association. Diagnostic and statistical manual of mental disorders: DSM-IV TR. Washington, DC: American Psychiatric Association; 2000

24. Skoog I, Nilsson L, Landahl S, Steen B. Mental disorders and the use of psychotropic drugs in an 85-year-old urban population. Int Psychogeriatr. 1993;5:33-48.

25. van't Hof MA, Burema J. Assessment of bias in the SENECA study. Eur J Clin Nutr. 1996;50(Suppl 2):4-8.

26. Shiovitz-Ezra S, Ayalon L. Use of direct versus indirect approaches to measure loneliness in later life. Res Aging. 2012;34:572-91.

27. Borys S, Perlman D. Gender differences in loneliness. Personal Soc Psychol Bull. 1985;11:63-75,

28. Rico-Uribe LA, Caballero FF, Martin-Maria N, Cabello M, Ayuso-Mateos JL, Miret M. Association of loneliness with all-cause mortality: a meta-analysis. PLoS One. 2018;13(1):e0190033. https://doi.org/10.1371/journal.pone. 0190033 PubMed PMID: 29300743; PubMed Central PMCID: PMCPMC5754055.

29. Holwerda TJ, Beekman AT, Deeg DJ, Stek ML, van Tilburg TG, Visser PJ, et al. Increased risk of mortality associated with social isolation in older men: only when feeling lonely? Results from the Amsterdam Study of the Elderly (AMSTEL). Psychol Med. 2012;42(4):843-53. https://doi.org/10.1017/ S0033291711001772 PubMed PMID: 21896239

30. Thurston RC, Kubzansky LD. Women, loneliness, and incident coronary heart disease. Psychosom Med. 2009;71(8):836-42. https://doi.org/10.1097/PSY ob013e3181b40efc PubMed PMID: 19661189; PubMed Central PMCID: PMCPMC2851545

\section{Publisher's Note}

Springer Nature remains neutral with regard to jurisdictional claims in published maps and institutional affiliations.

Ready to submit your research? Choose BMC and benefit from:

- fast, convenient online submission

- thorough peer review by experienced researchers in your field

- rapid publication on acceptance

- support for research data, including large and complex data types

- gold Open Access which fosters wider collaboration and increased citations

- maximum visibility for your research: over $100 \mathrm{M}$ website views per year

At $\mathrm{BMC}$, research is always in progress.

Learn more biomedcentral.com/submissions 